\title{
SACRAL ANTERIOR ROOT STIMULATORS FOR BLADDER CONTROL IN PARAPLEGIA
}

\author{
By G. S. Brindley, M.D., F.R.C.P., C. E. Polkey, M. D., F.R.C.S. and \\ D. N. Rushton, M.D., M.R.C.P. \\ M.R.C. Neurological Prostheses Unit and Neurosurgical Unit, The Maudsley \\ Hospital, London, England.
}

\begin{abstract}
Nine men and 2 women with spinal injuries have received radiolinked implants to stimulate the $\mathrm{S}_{2}, \mathrm{~S}_{3}$ and $\mathrm{S}_{4}$ anterior roots. By activating these they can empty their bladders at will with greatly reduced residual volumes, and the majority of them can achieve continence. Follow-ups are from two months to 4 years.
\end{abstract}

Key words: Paraplegia; implant; stimulator; bladder; sacral roots.

\section{Introduction}

AfTER the period of spinal shock, most patients whose bladders remain innervated by an isolated cord that is not severely damaged achieve reflex micturition. However, many of them have large residual urine volumes, and many have persistently or recurrently infected urine; and the large residual volume is probably important in the aetiology of the infection. Satisfactory continence is rarely achieved, at least in England, where the majority of male paraplegics use condom and leg-bag, and many female paraplegics wish that a urine-collecting device for women as efficient as the condom for men existed.

The conventional treatment of chronic retention in male paraplegics by drainage operations such as external sphincterotomy or bladder neck resection results in permanent incontinence requiring the wearing of a urinal device. Not surprisingly, many paraplegics prefer to remain reasonably continent and run the risks associated with a large residual volume and a high voiding pressure. About half of the paraplegic population have chronic or recurrent urinary infection, and many show progressive deterioration in the urinary tract and renal function on serial IVPs. According to Hackler's survey of American paraplegics in 1977, about $25 \%$ of paraplegics die within 25 years of their injury from renal failures.

It is for these reasons that various kinds of electrical implant have been tried for emptying the bladder. These have employed electrodes on the bladder wall (Bradley et al., I962; Hald et al., I967; Stenberg et al., I967; Halverstadt and Parry, I975; Merrill, I975), on the sacral nerves (Habib, I967), or on the conus medullaris (Nashold et al., I972; Sarramon et al., I979). Direct bladder stimulation requires strong current pulses which are liable to cause a flexion reflex and may be painful if the spinal lesion is incomplete. Electrode breakages are common because of the considerable movement that accompanies bladder contraction. For conus medullaris stimulators, nine long-term successes have been reported among I 2 patients (Nashold, I976), but the only published report other than from 
Nashold's unit has been much less favourable (Sarramon et al., 1979).

Brindley (1973, 1977) reported the development and animal testing of an implant that closes the urethra or empties the bladder, depending on how it is used. We here report the results of implanting sacral anterior root stimulators of this type in a series of I I patients with traumatic lesions of the spinal cord, with a follow-up of 2 to 50 months.

\section{Patients}

Eleven patients with traumatic cord lesions have had sacral root stimulators implanted between April 1978 and March I982. Six have complete paraplegia, one an incomplete paraplegia, three complete C6 lesions and one a C6 lesion with posterior column sparing. The level and duration of lesions and the state of the bladders preoperatively are summarised in Table Ia.

Although the bladders ranged from inactive through reflex to small and irritable, all patients had occasional, recurrent or persistent urinary tract infections.

\section{Implant}

The implant consists of three main parts. The electrode 'books' in which the sacral roots are trapped (Fig. Ia) are similar to those described by Brindley (I977) except that in patients 2-I I there were three electrodes in each slot, the centre electrode being the cathode and the two end electrodes being anodes. The tripolar arrangement ensures that stimulating current does not spread outside the slot and stimulates unwanted structures. This arrangement of electrodes can also be used to provide selective stimulation of small myelinated fibres while blocking large myelinated fibres (see Anodal Blockade below), and when, as in cases 3-I I, the tripolar electrodes are asymmetrically arranged, one-way anodal blockade can be achieved (Brindley and Craggs, I980). There are two electrode books. The upper may contain three slots (as in Fig. Ia) or two. The lower always contains only one slot.

The cables are helically wound in $90 \%$ platinum- $10 \%$ iridium polyimide-insulated $0.125 \mathrm{~mm}$ on a silicone rubber core and coated with silicone rubber (Copper, unpublished).

The radio receiver blocks employ conventional passive radio receiving circuits either with three separate coils or with three superimposed morphognostic coils (Donaldson, 1979). The cables are tunnelled under the skin from near the electrode site to the receiver site, where they are connected to the receivers through a connecting block devised for the purpose (Brindley, 1975), or more recently with the miniature plug and socket connectors shown in Figs Ib \& 2a (Craggs, unpublished). All parts of the implants, as well as the external stimulating apparatus (Fig. 2b), were designed and made in the Neurological Prostheses Unit.

\section{Surgery}

The implant operation is usually done in two stages separated by about a week. In the first stage a laminectomy of $\mathrm{L}_{3}$ to $\mathrm{L}_{5}$ and the first part of the sacrum is done, the dura opened and the root identified by their size and situation. Their response to stimulation is tested using a small hook 
TABLE Ia

Summary of preoperative neurological and urological state. No patient was reliably continent. $\mathrm{S}=$ external urethral sphincterotomy. $\mathrm{B}=$ transurethral resection of the bladder neck.

\begin{tabular}{|c|c|c|c|c|c|c|c|c|c|c|c|c|c|}
\hline Case & Sex & Age & $\begin{array}{l}\text { Years } \\
\text { Duration }\end{array}$ & $\begin{array}{l}\text { Lesion } \\
\text { level }\end{array}$ & $\begin{array}{r}\text { Blad } \\
\text { Capacity }\end{array}$ & $\begin{array}{l}\text { der condit } \\
\text { Residual }\end{array}$ & $\begin{array}{l}\text { ion } \\
\text { Reflex }\end{array}$ & $\begin{array}{l}\text { Trabeculation } \\
\text { Hypertrophy }\end{array}$ & $\begin{array}{l}\text { Ureteric } \\
\text { Reflux }\end{array}$ & $\begin{array}{c}\text { Bladder } \\
\text { Neck } \\
\text { incompetent }\end{array}$ & $\begin{array}{l}\text { Previous } \\
\text { surgery }\end{array}$ & $\begin{array}{l}\text { Renal } \\
\text { changes }\end{array}$ & $\begin{array}{l}\text { +ve } \\
\text { urine } \\
\text { cultures }\end{array}$ \\
\hline I & $M$ & 38 & 3 & $\mathrm{~T} 6$ & 400 & Catheter & $(+)$ & + & & & S, B & + & $6 / 7$ \\
\hline 2 & M & 38 & 3 & TI2 & 800 & 500 & $(+)$ & ++ & + & + & - & - & $2 / 7$ \\
\hline 3 & $M$ & 33 & I I & $\mathrm{T}_{9}$ & 750 & 500 & $(+)$ & ++ & - & - & - & $(+)$ & $8 / 33$ \\
\hline 4 & $M$ & 43 & I3 & C6́ & 800 & 800 & + & + & - & - & - & - & $0 / 2$ \\
\hline 5 & M & 28 & I & TIO & 450 & 350 & + & + & + & - & - & - & $2 / 4$ \\
\hline 6 & $\mathrm{~F}$ & $4 \mathrm{I}$ & 5 & T8 inc & 250 & 20 & + & + & - & - & - & - & 9/I I \\
\hline 7 & $\mathbf{M}$ & 32 & 5 & $\mathrm{~T}_{5}$ & 200 & I 50 & $++t$ & ++ & - & + & $S$ & + & $1 / 3$ \\
\hline 8 & $M$ & 24 & 3 & $\mathrm{~T}_{7}$ & 850 & Catheter & - & $(+)$ & + & + & - & + & 13 \\
\hline 9 & M & 27 & 8 & C6 inc & 300 & 200 & ++ & ++ & & + & B & - & $4 / 4$ \\
\hline IO & $\mathrm{F}$ & 26 & 8 & C6 & 600 & 20 & $(+)$ & ++ & - & - & - & $(+)$ & 9/16 \\
\hline I I & $M$ & 24 & I & C6-8 & 250 & Catheter & + & + & - & + & - & - & I6/17 \\
\hline
\end{tabular}



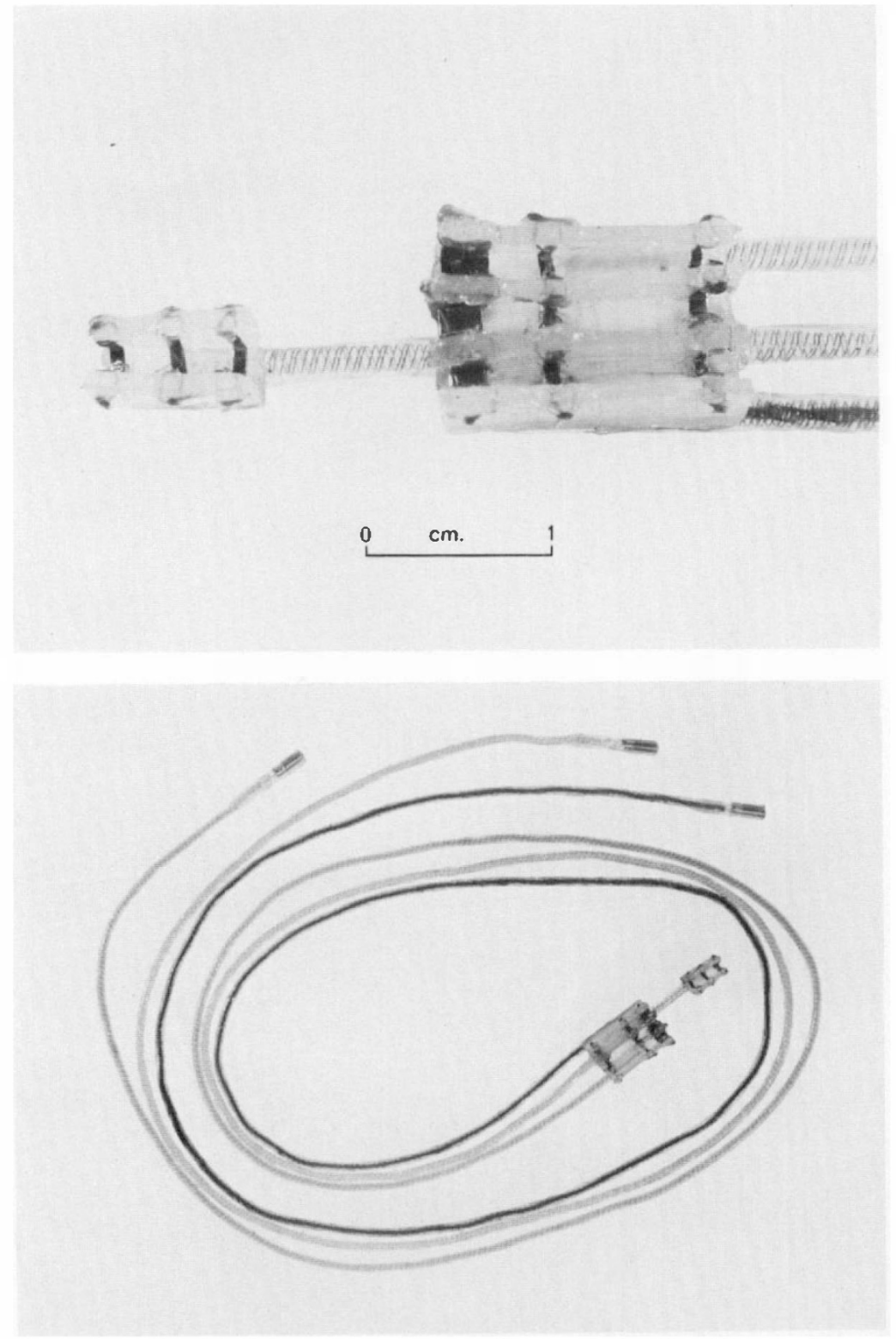

FIG. I

a. The sacral root electrodes used for patient 9. The $S_{2}$ anterior roots were placed in the lateral slots of the upper (three-slot) 'book', and the $S_{3}$ anterior roots together in the middle slot. The $\mathrm{S}_{4}$ and $\mathrm{S}_{5}$ roots were placed in the lower (one-slot) 'book'.

b. Electrode and cable assembly. The three cable cores are colour coded for identification. 

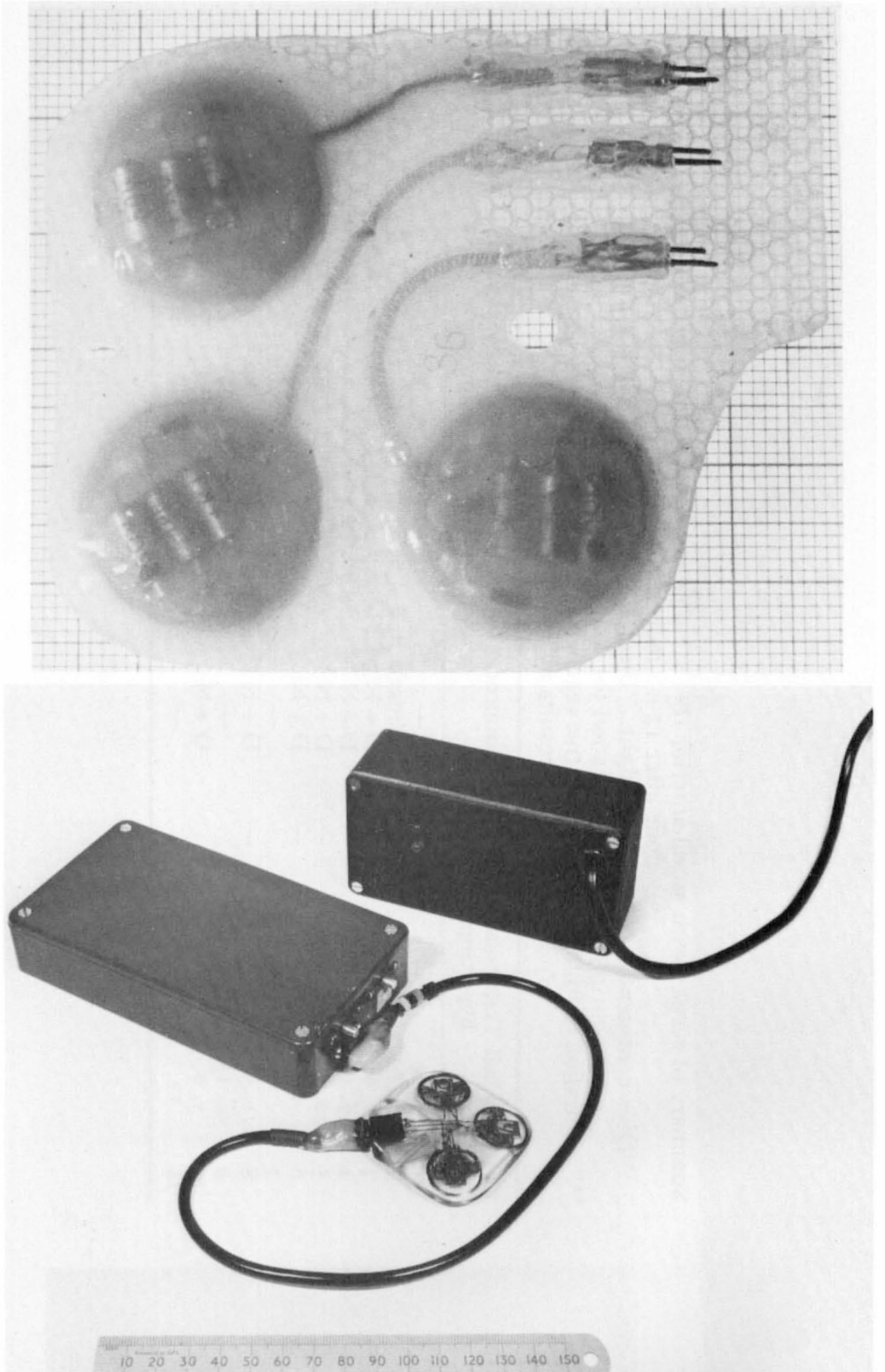

FIG. 2

a. The three passive implanted receivers, with plug connectors. b. The external transmitter and its controller and charger. 


\section{TABLE Ib}

Summary of results with sacral anterior root stimulator. Follow-up cystometry is done after I2-I 8 months.

'D' = continent by day, 'N' by night. 'Buzz' = continent only when using continuous weak stimulation for sphincter. See Fig. 7.

' $\star$ ' = duration of follow-up after effective regeneration of damaged roots. Symbols identify results in Fig. 4.

\begin{tabular}{|c|c|c|c|c|c|c|c|c|}
\hline Case & Residual & $\begin{array}{l}\text { Trabeculation } \\
\text { hypertrophy }\end{array}$ & $\begin{array}{c}\text { Ureteric } \\
\text { reflux }\end{array}$ & Continence & $\begin{array}{l}\text { Evoked } \\
\text { erection }\end{array}$ & $\begin{array}{l}\text { + ve urine } \\
\text { cultures }\end{array}$ & $\begin{array}{l}\text { Months } \\
\text { follow-up }\end{array}$ & Symbol \\
\hline I & 19,29 & + & 一 & - & + & $7 / 7$ & 50 & 约 \\
\hline 2 & II 4,62 & $(+)$ & + & $\mathrm{N}$ (buzz) & - & $4 / 5$ & $47\left(37^{\star}\right)$ & $\square$ \\
\hline 3 & II, 6 I & ++ & - & $\mathrm{D}+\mathrm{N}$ & + & $\mathrm{I} / 7$ & 39 & $\Delta$ \\
\hline 4 & 12,13 & + & - & $\mathrm{D}+\mathrm{N}$ & + & $4 / 6$ & 35 & $\star$ \\
\hline 5 & 20,90 & - & - & $\mathrm{D}+\mathrm{N}$ & - & $5 / 7$ & 32 & $\star$ \\
\hline 6 & $<\mathrm{I}$ & - & - & $\mathrm{D}+\mathrm{N}$ & $\mathrm{F}$ & $\mathrm{I} / 4$ & 30 & 0 \\
\hline 7 & & & & - & - & - & $2 \mathrm{I}\left(6^{\star}\right)$ & 0 \\
\hline 8 & I I, 50 & - & - & $\mathrm{D}+\mathrm{N}$ & - & $\mathrm{I} / 2$ & 20 & [ \\
\hline 9 & $39, I 3$ & & & - & + & $I / 2$ & I I & \\
\hline IO & 5,9 & & & $\mathrm{D}+\mathrm{N}$ & $\mathrm{F}$ & $I / 3$ & 4 & \\
\hline I I & 37 & & & - & + & - & 2 & \\
\hline
\end{tabular}




\section{TABLE II}

Responses evoked by stimulation of roots identified at operation as being $S_{2}, S_{3}$, and $S_{4} / 5$. Patient 8 is omitted since the anatomy of his sacral roots was anomalous and asymmetrical

\begin{tabular}{|c|c|c|c|}
\hline & $\mathrm{S}_{2}$ & $\mathrm{~S}_{3}$ & $\mathrm{~S}_{4} / 5$ \\
\hline \multicolumn{4}{|l|}{ Lower limb } \\
\hline Biceps femoris & $\mathrm{I}, 2,3,4,5,6,7,9$, Iо & $\mathrm{I}, 5, \mathrm{IO}$ & \\
\hline Glutei & I, $2,3,4,5,6,7,9$, IO, I I & & \\
\hline Gastroenemius/soleus & I, $2,3,4,5,6,7,9$, IO, I I & 9, IO & \\
\hline $\begin{array}{l}\text { Toe flexors } \\
\text { Pelvic floor }\end{array}$ & $\mathrm{I}, 2,3,4,5,6,7,9$ & I, $2,3,4,5,6,7,9$, I०, I I & \\
\hline Levator ani & & $2,3,4,5,9$ & $2,3,4,10$ \\
\hline Anal sphincter & & $2,3,4,5,7,9$, Io & $\mathrm{I}, 2,3,4,6,7,9, \mathbf{1}$, I I \\
\hline Ischio cavernosus & $\mathbf{I}, 3,7,9, \mathbf{I}$ & I, $2,3,4,5,6,7,9$, Iо, I I & $2,3,4,7,9$, IO, I I \\
\hline $\begin{array}{l}\text { Urethral sphincter } \\
\text { Parasympathetic }\end{array}$ & 4 & $2,3,4,5,6,7,9$, IO, I I & $2,3,4,5,6,9$, IO, I I \\
\hline Erection & I, 9 & 3,4, I I & \\
\hline $\begin{array}{l}\text { Detrusor } \\
\text { Reflex }\end{array}$ & 4 & $\mathrm{I}, 2,5,6,7,9$, Iо, I I & $2,3,5,7$, IO, I I \\
\hline Abdominal muscles & IO & 8 & 5 \\
\hline Abolition of erection & 4,5 & 5 & $\mathrm{I}, 2,5$ \\
\hline Dartos & $I, 2,4,5$ & $I, 2,3,4,5,7$ & I, $4,5,7$ \\
\hline Sweating & I & I & I \\
\hline Piloerection & $\mathbf{I}, \mathbf{I O}$ & I, 7 & I \\
\hline
\end{tabular}


electrode. The anterior and posterior roots of the $S_{2}$ and usually the $S_{3}$ segments are identified, and separated so that the anterior roots alone can be trapped in the book. S4 roots are not separated into anterior and posterior, as they are too small.

In some of the patients (cases $2,3,4,5,8$ ) we used an implant with a two-slot upper book, and placed the $\mathrm{S}_{2}$ anterior roots in one slot of the upper book, the $S_{3}$ anterior roots in the other slot of the same book, and the $\mathrm{S}_{4}$ and $\mathrm{S}_{5}$ roots, anterior and posterior, in the lower single-slot book. In four patients (cases I, 9, IO \& I I) we used a three-slot upper book, and placed the left and right $S_{2}$ anterior roots in its left and right slots respectively and the left and right $S_{3}$ anterior roots together in its centre slot. In the case with sensation on one side (case 6) the left $S_{2}$ and $S_{3}$ anterior roots were placed together in the left slot of a 2-slot upper book, and the corresponding right roots in the right slot. This was done to allow the possibility of stimulating S2, 3 on one side only if the other side proved too painful. The $S_{4}$ and $S_{5}$ roots were placed, as usual, in the lower book. In one case (8) the anatomy was anomalous, and we are not sure what the segmental numbers of the roots that we used.

When the roots are in their slots the responses are checked by stimulation through the implant electrodes and the dura closed. Where the cables pass through the dura a seal against CSF leakage is obtained by means of a grommet made of fine woven polyester outside and silicone rubber inside (Brindley, I98I), which is glued around the cables. In four of our first six patients, before this device was invented, CSF tracked along the cables and formed a swelling over the receiver block. Two of these leaks stopped spontaneously and two needed repair operations. There have been no leaks in the last five patients, in whom grommets have been used.

The cables are led to a separate incision over the left lower anterior chest wall using a trocar, and left under the skin.

At the second stage operation the anterior skin incision is reopened, the cables are found and connected to the receivers. The receivers are implanted subcutaneously over the low left ribs and costal cartilages. It is preferable to identify the cables before connecting them, and each has a differently coloured core for this purpose. The individual conductors in each cable have also to be identified so that the cathodal output of the radio receiver can be connected to the centre electrode and the anodal output to the other two electrodes. We do this by putting electrical pulses in through the cables and recording them through electrodes on the skin. We tried, but abandoned, coding the wires with coloured enamel.

\section{Electrical calibrations}

\section{Wire and electrode identification}

During the second stage operation, lumbar skin electrodes connected with low gain to an EEG machine will show the skin pulses caused by briefly tapping pairs of wires in one cable with a battery probe. The largest pulse comes from the largest dipole, and those two wires are connected to the positive side of the receiver output. The remaining wire is connected to the negative side. Since the introduction of plug and socket connectors (from Case 9), this wire identification has become necessary. 


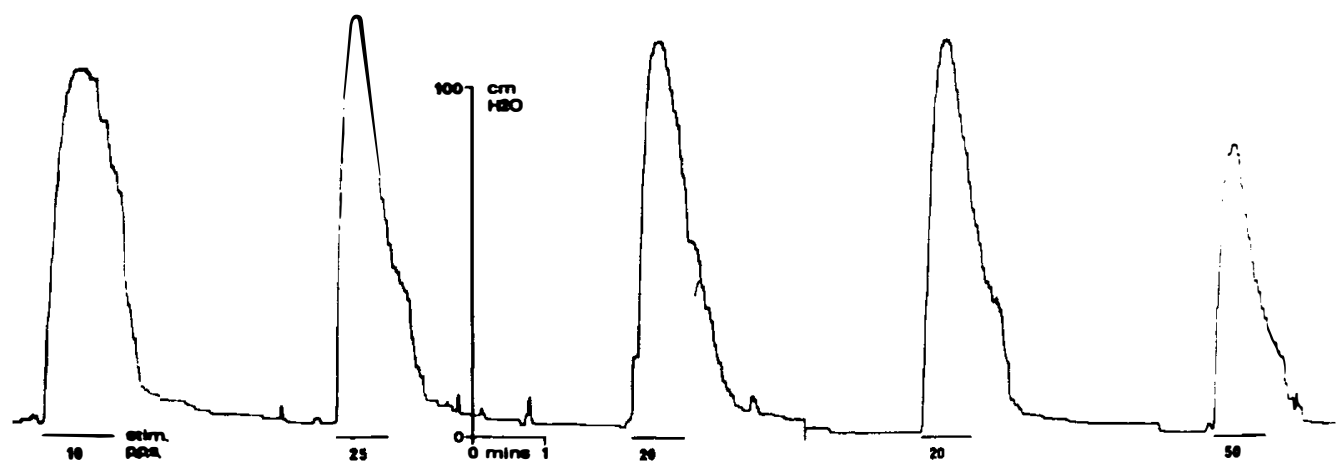

FIG. 3

Static vesical pressure measured while stimulating the $S_{3}$ roots (patient $I$ ) maximally at different rates.

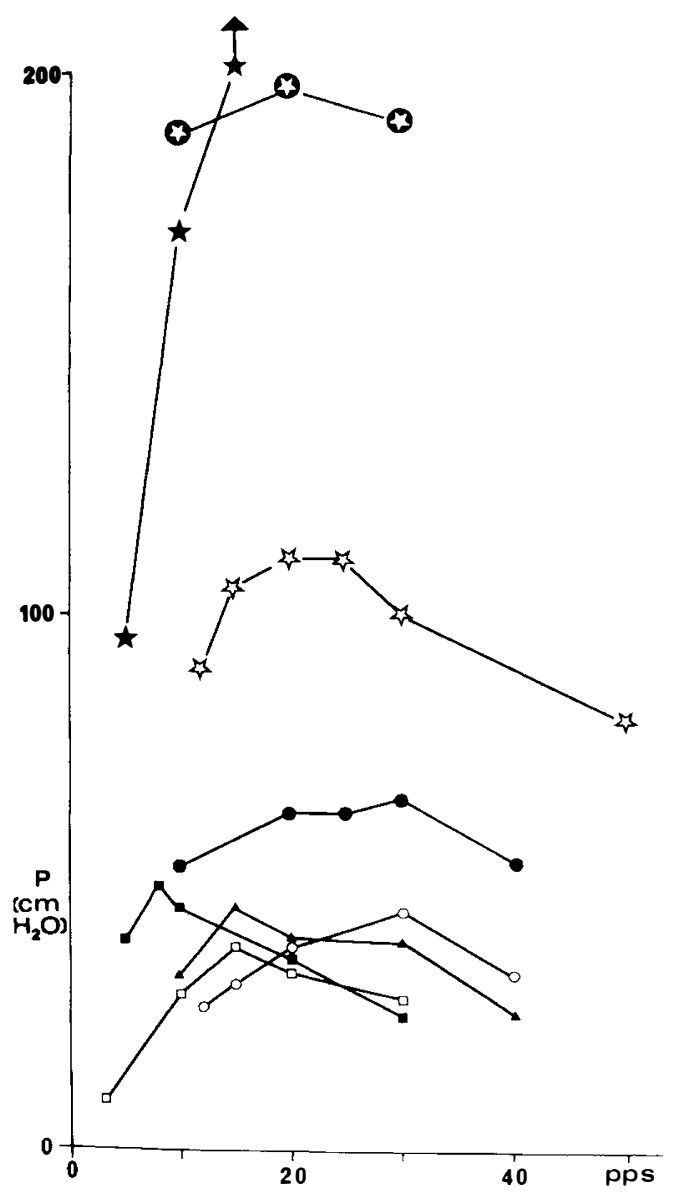

FIG. 4

Relation between vesical pressure and stimulation rate for patients $\mathrm{I}-8$. The symbols are keyed in Table $\mathrm{I}$. The optimum rate varies between $8-30 / \mathrm{sec}$ for the various patients. 


\section{Pulse current measurement}

Just after placing the roots in their slots during the first stage, or before connecting the cables to the receiver during the second stage, the electrode impedance and the threshold pulse current for somatic movement are recorded by measuring on an oscilloscope the voltage from across the electrodes, and the voltage across a Io-ohm resistor in series with the electrodes. The pulse current required for detrusor activation could be measured in the same way, but in practice it is too time-consuming to do during the operation and is measured later as a multiple of the somatic threshold. The somatic threshold pulse current varies between patients and roots in the range $0.3-3.0 \mathrm{~mA}$, and the pulse current for maximal detrusor response in the range 5-20 $\mathrm{mA}$. The impedance for $O . \mathrm{I} \mathrm{msec}$ pulses and tripolar electrodes is in the range $300-500 \mathrm{ohms}$.

\section{Innervation}

Table 2 shows that the somatic innervation is fairly constant between our I I subjects. S2 innervates a variety of muscles in the lower limb, usually the biceps femoris, glutei, calf muscles and tow flexors. $S_{3}$ innervates the muscles of the pelvic floor and usually also the tow flexors, and $\mathrm{S}_{4}$ the pelvic floor alone. Ischiocavernosus usually responds rilore strongly to $S_{3}$ than $S_{4}$, and the anal sphincter more strongly to $S_{4}$ than $S_{3}$.

The parasympathetic innervation is more variable. Among our patients the commonest pattern is for $\mathrm{S}_{3}$ to carry the principal detrusor innervation, with a contribution from $\mathrm{S}_{2}$ or $\mathrm{S}_{4}$, but there are examples where the innervation is principally from $S_{2}$ or $S_{4}$, with a contribution from $S_{3}$.

\section{Detrusor Responses}

Besides determining which roots are to be stimulated, the optimum frequency and strength of stimulation have to be determined. This is most conveniently done in the immediate postoperative period while the patient is still catheterised. We stimulate at various strengths through each root pair in turn, and then at various pulse rates at the just-supramaximal level. Stimulation is usually continued for $30 \mathrm{sec}$. in each trial, as by that time the bladder pressure has reached a peak and started to decline. Provided 3-4 minutes elapse between stimulations, the pressure from repeated stimulations varied by less than $5 \%$. Stimulation at low pulse rates gives a slow-rise response fatiguing slowly, and high-frequency stimulation gives a rapid response fatiguing quickly. Fig. 3 shows a representative record from this sort of test, and Fig. 4 summarises the pulse-rate data from the first eight patients. It shows that for the majority the greatest pressure is reached for continuous stimulation at a rate 25-30 pulses/sec, but that some patients require a lower rate ( 15 and 8 pulses $/ \mathrm{sec}$ ). For patients in whom the detrusor was well innervated by more than one root pair, the pulserate/pressure characteristic was similar for both detrusor-stimulating root pairs.

\section{Intermittent Stimulation}

In most people the unfatigued external sphincter is strong enough to prevent 
micturition, and in most of our patients the external sphincter is activated during detrusor stimulation, as they are innervated through the same roots. There are three possible ways of overcoming this difficulty. The first takes advantage of the fact that the large myelinated fibres to the striated sphincter can be stimulated maximally by pulses weak enough not to stimulate the fine myelinated fibres to the detrusor; a fatiguing burst at this strength is then followed by strong stimulation to activate the detrusor. The second is to stimulate strongly in bursts (Fig. 5). Such bursts will activate the external sphincter intermittently, but if the intervals are not too long the detrusor will contract continuously (Brindley, I977), so that micturition occurs between the bursts. The third is to block the large myelinated fibres to the external sphincter anodally without blocking the small myelinated parasympathetic fibres (Brindley and Craggs, I980).

The disadvantage of the first method is that the external sphincter is rather resistant to fatigue; in practice it works so poorly in baboons that we have made no great efforts to get it working in our patients. The disadvantage of the second method is that an artificial pattern of micturition is used, with voiding in spurts each a few seconds long. Since voiding is interrupted, voiding pressure may be intermittently higher than normal. We have not yet succeeded in making the third method work well enough in patients for everyday use. In practice, ten of our patients use the second method and the eighth (case I) has had a previous sphincterotomy and can void continuously.

\section{Cystometry}

Patients had preoperative IVP and cystometry to establish the initial state of the urinary tract (Table Ia). Postoperative cystometry was directed towards the correct stimulation parameters (Figs 3,4), and in those patients in whom it was indicated, follow-up cystometry including voiding pressures was done. We did not initially have a firm view on whether ureteric reflux and established abnormalities of the bladder such as hypertrophy and trabeculation or diverticula would be likely to improve or deteriorate. On the one hand voiding pressure might be intermittently higher than previously, since outflow is, except in case I, obstructed during each stimulating burst; on the other hand improved emptying should reduce the habitual bladder size, and therefore the wall tension, during filling. The effects so far of sacral root stimulation on bladder health are summarised in Table Ib. Follow-up IVPs have as yet shown detectable deterioration in only one patient (case 3; slight increase in calyceal clubbing), although several more years of follow-up will be needed. In the three cases $(2,5$ and 8) with first degree ureteric reflux preoperatively we screened the contrast-filled bladder during cystometry while stimulating the relevant roots soon after the operation and at 45, 28 and I 6 months respectively. The degree of ureteric reflux that was present preoperatively was no worse at the early postoperative test, nor was it made worse by stimulation. By February I 982 cases 5 and 8 had ceased to reflux, either during filling or during implant-driven stimulation. In case 2 after 45 months of followup, spontaneous ureteric reflux continued to occur on filling to $250 \mathrm{ml}$ (right ureter), and $300 \mathrm{ml}$ (left ureter). Implant-driven voiding did not cause any reflux, nor did spontaneous reflux extend above the pelvic brim. 


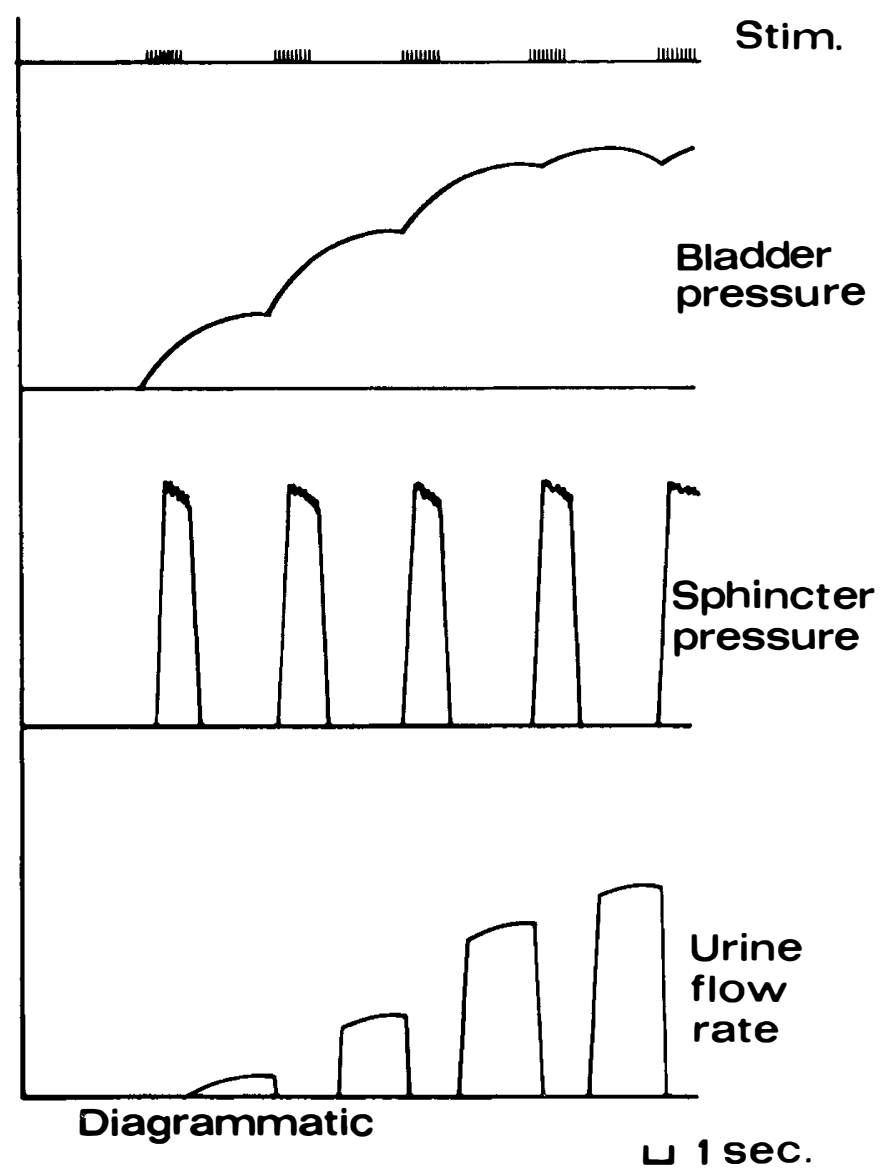

FIG. 5

a. Diagramillustrating voiding with bursts of stimulation. The optimum burst and interval lengths vary between patients.

\section{Voiding Pressure}

In the three patients whose bladder pressure was capable of exceeding $50 \mathrm{~cm}$ of water and who had intact sphincters (patients 4, 5 and 8) and in patients 2 and 6, bladder pressures were measured through a thin urethral catheter during implant-driven micturition after the implants had been in use for many months. In patient 2, 4, 6 and 8 the maximum voiding pressures were acceptable by our criteria $(22,75,35,35 \mathrm{~cm} \mathrm{H} 2 \mathrm{O})$, in spite of the intermittent obstruction to voiding presented by the external sphincter. In patient 5 the maximum voiding pressure was over $100 \mathrm{~cm}$ $\mathrm{H}_{2} \mathrm{O}$. We therefore lowered the frequency given by his stimulator from 25 to I 5 pulses/sec. He then voided with residual less than $50 \mathrm{ml}$ as assessed by screening during voiding, with maximum voiding pressure $70 \mathrm{~cm} \mathrm{H} 2 \mathrm{O}$. Patients 2, 5, 6 and 8 now show on IVP clear evidence of reversal of hypertrophy and trabeculation of the bladder after $\mathrm{I} \frac{1}{2}$ to 3 years of voiding using the stimulator; the serial films for patient 2 are shown in Fig. 6. 


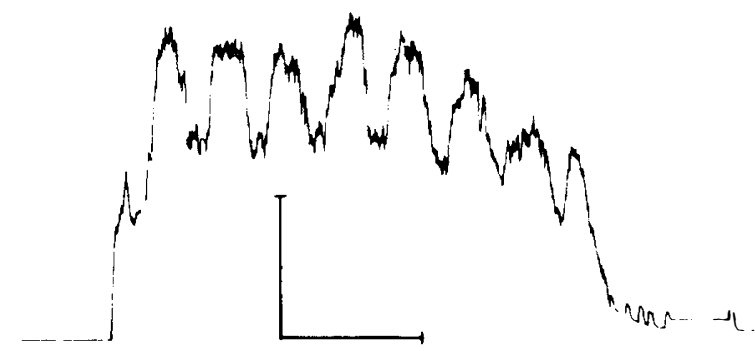

b. Urine flow record from patient 6, using burst stimulation. The urine flow is partially cut off during the stimulation bursts in this patient. Peak voiding pressure in this condition was $35 \mathrm{~cm} \mathrm{H} 2 \mathrm{O}$. Calibrations $5 \mathrm{ml} / \mathrm{sec}$, $\mathrm{IO}$ sec.

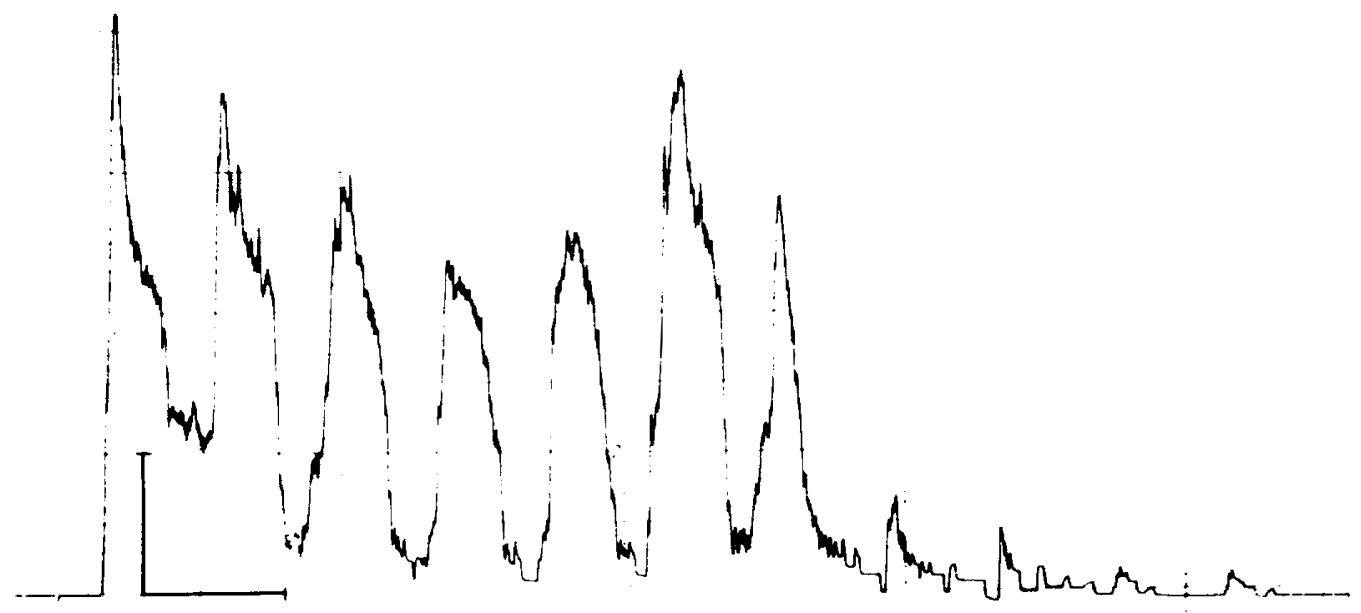

c. Urine flow record from patient IO. In this patient the external sphincter is strong enough to occlude the urine flow completely during part of the voiding. Peak voiding pressure in this condition was $55 \mathrm{~cm} \mathrm{H} 2 \mathrm{O}$. Calibrations $5 \mathrm{ml} / \mathrm{sec}$, $10 \mathrm{sec}$.

\section{Residual Urine Volume}

Residual urine volumes given in Table Ia were measured by catheter or estimated from post-micturition films during IVP or cystometry. The same methods were also used for follow-up residual measurements (Table Ib), but where the patient was continent we preferred to use a modification (Rushton and Brindley, unpublished) of a non-catheter dye dilution method (Cotran and Kass, 1958). The non-catheter method is more accurate than the others, particularly for small residuals, but does require continence for 4 hours. In all cases the postoperative residual volume is less than $100 \mathrm{ml}$, and in 7 cases it does not exceed $50 \mathrm{ml}$. We regard this as one of the main reasons for the improvements in bladder morphology and loss of reflux.

\section{Damage to Nerve Roots}

Brindley (1977) showed that in the baboon ventral roots that were deliberately damaged and degenerated while trapped in an implant sub- 


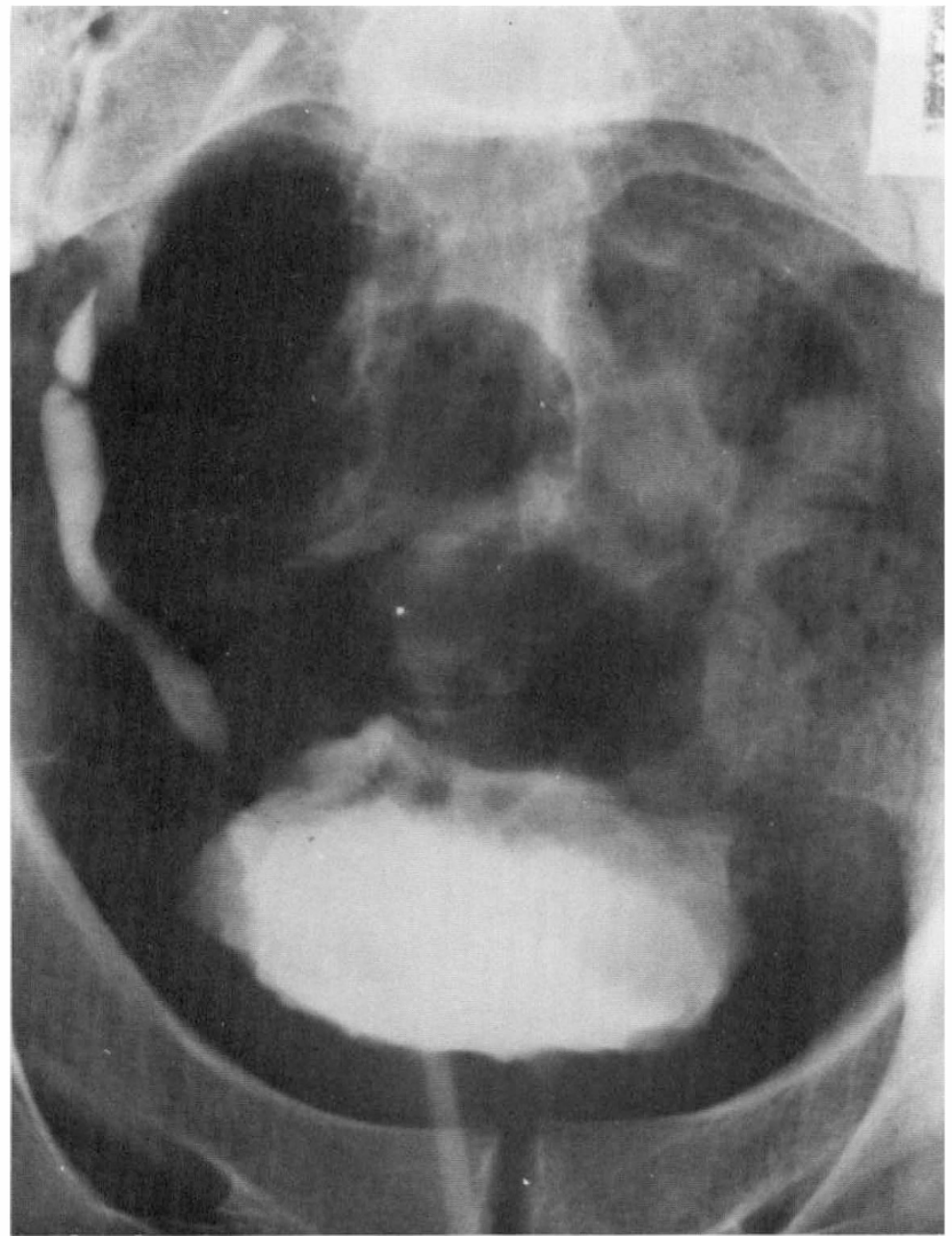

FIG. 6

Serial bladder films taken from IVPs in case 2 to illustrate reduction of bladder hypertrophy.

a. Preoperative (May I978)

sequently regenerated to give the same movements as before. In patients the ventral roots were not, of course, deliberately injured at the time of operation, but in several cases there was considerable fibrosis and tethering of the roots (probably owing to the organisation of subarachnoid blood clot following the original injury) so that the dissection was long and difficult. In two of these (cases 2 and 7) roots which were excitable during the operation gave feeble and incomplete somatic responses when tested subsequently, and detrusor contractions that were inadequate for micturition. In case 2 , recovery of both pelvic floor and parasympathetic response took place some 8-IO months postoperatively, after which the implant worked satisfactorily. In case 7, recovery sufficient to allow radiodriven micturition took over I I months, but the implant is now in regular use. This patient had a small irritable bladder, and to treat this both $\mathrm{S}_{2}$ 

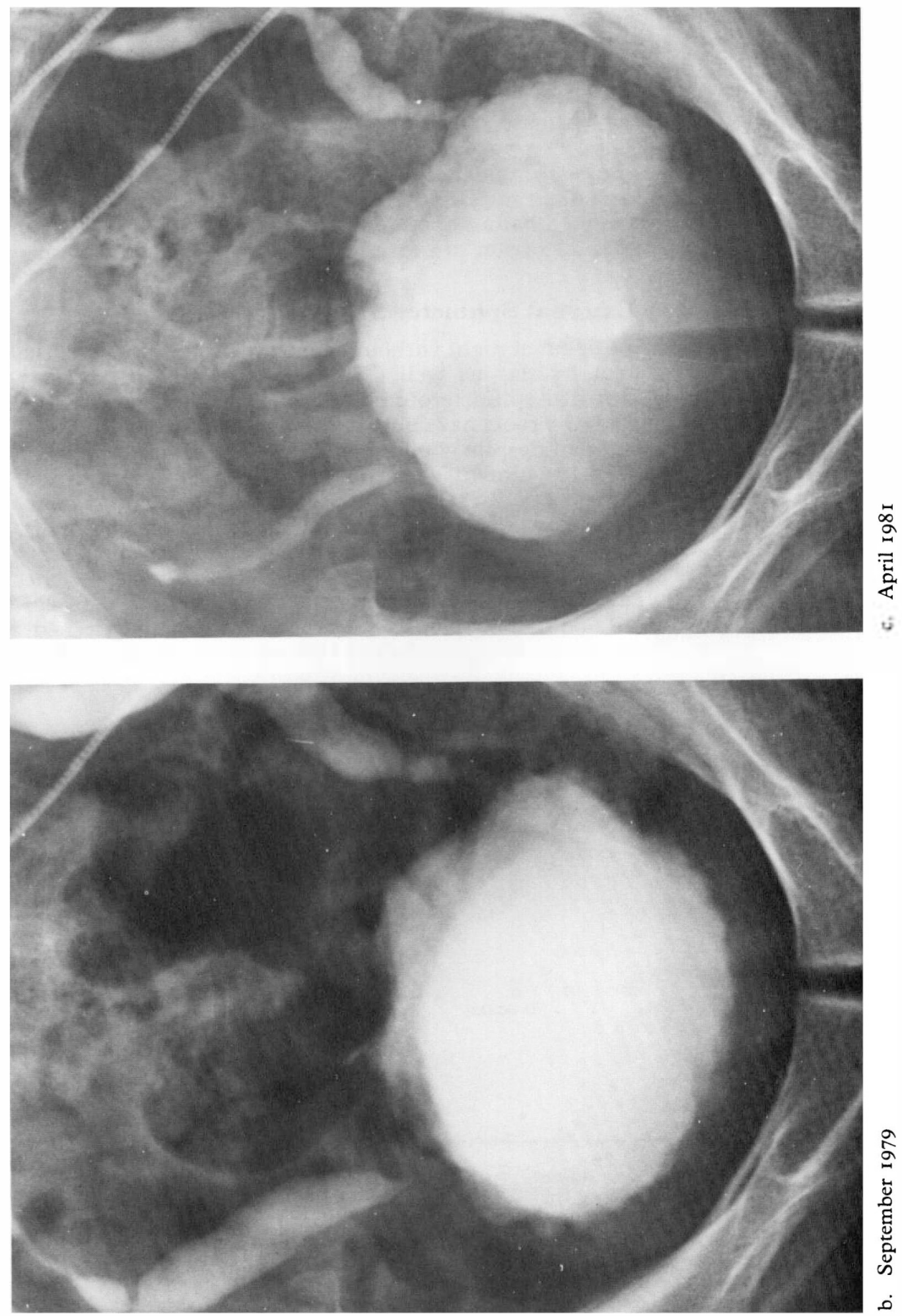
posterior roots and the right $\mathrm{S}_{3}$ posterior root were cut. Posterior roots were not cut in any of the other patients, but in patient 6 (incomplete lesion) postoperative sensory testing showed fresh loss of left $S_{3}$ distribution. Since 7 of the other patients have complete lesions, we do not know whether accidental injury to posterior roots occurred in them. There is indirect evidence for such injury in one of them, in that his tonic glandipudendal reflex (Gillan and Brindley, 1979) is now present only on one side. It was not examined before operation (the reflex being at that time unknown), but there is no reason to expect it to have been asymmetrical.

\section{External Sphincter Stimulation}

Seven patients are continent at night without sphincter stimulation, and six of these are continent by day as well (Table I). Of the incontinent patients, patient I has had sphincterotomy (twice) and bladder neck resection, and in patient 7 the roots have not yet fully regenerated. Patient 2 remained often incontinent despite good emptying and an intact sphincter. We therefore arranged for him to glue the transmitter in position and stimulate $S_{3}$ continuously at night, at a strength sufficient to activate somatic but not parasympathetic nerve fibres. For the first I03 nights he left his condom urinal device on at night, and recorded the overnight leaked volume and the volume on first avoiding in the morning. Fig. 7 summarises the results of this test, and shows that with continuous stimulation the external sphincter is capable of maintaining continence at least while resting in bed. Leakage occurs either when overnight bladder volume is very large or when

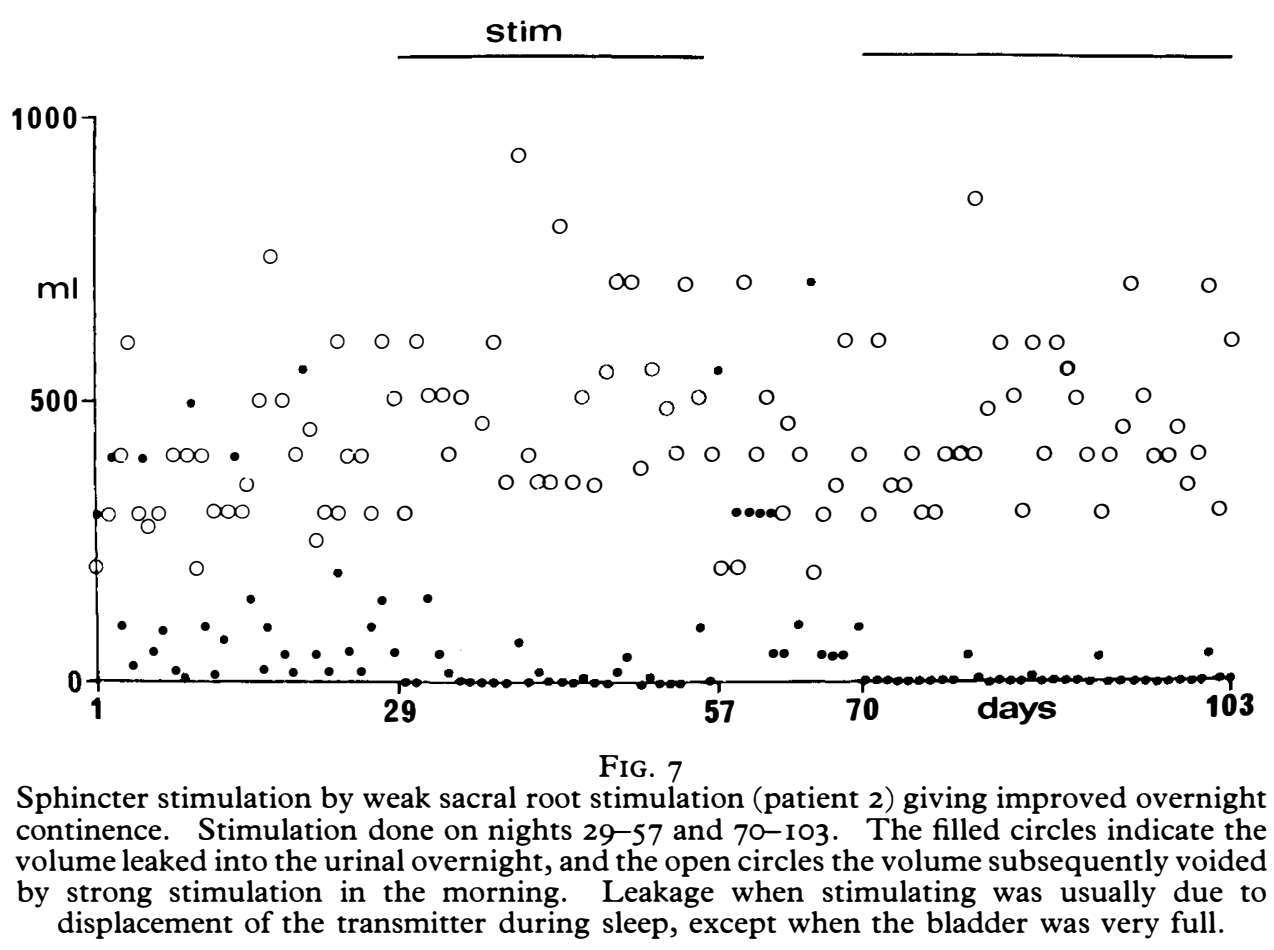


the transmitter becomes displaced. The fatigued external sphincter alone is not, however, capable of maintaining continence in this patient while he is active in his wheelchair. Patient I I resembles patient 2, but he has so far established only partial continence by using sphincter stimulation.

\section{Erection}

In 5 of the 9 male patients, penile erection can be achieved by strong stimulation of $S_{2}$ or $S_{3}$ applied continuously (IO-30 pulses/sec for $\frac{1}{2}-2$ minutes, and sustained with continuing stimulation for at least ro minutes.

Acknowledgements: The implantable cables and receivers for the first 9 patients were made by Miss Judy Jackson. The preoperative urodynamic assessments (and some postoperative) were done by Dr Linda Cardozo.

\section{REFERENCES}

Bradley, W. E., Wittmers, L. E., Chou, S. N. \& French, S. A. (I962). Use of a radio transmitter receiver unit for the treatment of neurogenic bladder. A preliminary report. F. Neurosurg., 19, 782-786.

BRINDLEY, G. S. (I973). Emptying the bladder by stimulating sacral ventral roots. $\mathcal{F}$. Physiol., 237, I 5-I6P.

BRINDLEY, G. S. (I975). A method for making and insulating many electrical connexions in an implant at the time of implantation or during a subsequent surgical procedure. F. Physiol., 247, 2P.

BRINDLEY, G. S. (1977). An implant to empty the bladder or close the urethra. F. Neurol. Neurosurg. Psychiat., 40, 358-369.

BRINDLEY, G. S. (I98I). A grommet for preventing cerebrospinal fluid from leaking along the outside of implanted tubes and cables. F. Physiol., 320, IP.

Brindley, G. S. \& CragGS, M. D. (1980). A technique for anodally blocking large nerve fibres through chronically implanted electrodes. F. Neurol. Neurosurg. Psychiat., 43, $1083-1090$.

Cotran, R. \& Kass, E. (1958). Determination of the volume of residual urine in the bladder without catheterisation. New. Engl. F. Med., 259, 337-339.

DoNALDSON, N. DE N. (1979). Morphognostic coils: a technique for transmitting several nearfield radio signals through the same space. Med. E Biol. Eng. E Comput., 17, 27 I-274.

Gillan, P. \& Brindley, G. S. (I979). Vaginal and pelvic floor responses to sexual stimulation. Psychophysiology, 16, 47 I-48I.

HabiB, H. N. (1967). Experience and recent contributions in sacral nerve stimulation for voiding in both human and animal. Brit. $\mathcal{F}$. Urol., 39, 73-83.

HACKLER, R. H. (I977). A 25-year prospective mortality study in the spinal cord injured patient; comparison with the long-term living paraplegic. F. Urol., II7, 486-488.

Hald, T., Meier, W., Khalili, A., Agrawal, G., Benton, J. G. \& Kantrowitz, A. (1967). Clinical experience with a radio-linked bladder stimulator. F. Urol., 97, 73-78.

Halverstadt, D. B. \& PARRY, W. L. (I975). Electronic stimulation of the human bladder: nine years later. $\mathcal{F}$. Urol., 13, 34I-344.

MerRILL, D. C. (1975). Clinical experience with the Mentor bladder stimulator. III: patients with urinary vesical hypotonia. F. Urol., 113, 335-337.

Nashold, B. S., Friedman, H., GlenN, J. F., Grimes, J. H., BARRY, W. F. \& Avery, R. (1972). Electromicturition in paraplegia. Arch. Surg., 104, 195-202.

NASHOLD, B. S. (1976). Electric stimulation of the neurogenic bladder from the spinal cord. International Symposium on Electric Stimulation of the Neurogenic Bladder. Frankfurt, 5-6 March I 976.

Sarramon, J. P., Lazorthes, Y., Sedan, R., Leandri, P. \& Lhez, J. M. (I979). Neurostimulation médullaire dans les vessies neurogènes centrales. Acta Urol. Belg., 47, I29-138.

Stenberg, C. C., Burnette, H. W. \& Bunts, R. C. (1967). Electrical stimulation of human neurogenic bladders: experience with four patients. $\mathcal{F}$. Urol., 97, 79-84. 